\title{
Cómo se redimensiona la construcción social de la memoria en el México actual: un caso de arte interactivo
}

\section{How the social construction of memory is resized in present-day Mexico: a case of interactive art}

\author{
TIPO DE TRABAJO: Comunicación virtual.
}

\author{
PALABRAS CLAVE
}

Arte digital, memoria colectiva, estética; participación, instalación interactiva.

KEY WORDS

Digital art, collective memory, esthetic, participation, interactive installation.

RESUMEN

\begin{abstract}
La presente comunicación pretende analizar y reflexionar sobre el cómo se construye y se redimensiona el concepto de memoria colectiva a través del arte. La violencia que se ha suscitado en México a partir de la guerra contra el narcotráfico ha resultado en miles de desaparecidos y cientos de fosas clandestinas. Artistas como Rafael Lozano-Hemmer y su instalación interactiva "Nivel de confianza" (2015) han partido del uso de las tecnologías digitales para enunciar y pronunciar los problemas sociales violentos que se han suscitado en el país durante los últimos años. Más allá de utilizar el arte para representar los crímenes de lesa humanidad, lo que se pretende es promover una conciencia colectiva sobre el olvido, la amnesia y la aniquilación de la memoria ejercida por el Estado.
\end{abstract}

En ese sentido, se reflexionará sobre los textos filosóficos de Tzvetan Todorov y Paul Ricoeur, a fin de señalar cómo se involucra una sociedad con los eventos violentos de su pasado, la forma en que la afectan y el modo de asimilarlos.

El arte es manifestado, entonces, como una forma de significado que va más allá de la historia al representar el relato acontecido, pues nos lo presenta como parte de las identidades de los estudiantes desaparecidos de la Escuela Normal Rural "Isidro Burgos". Así pues, a través del proceso de interacción y el entrecruce de información, los usuarios de la instalación construyen su propio espacio de reflexión en el que convergen diferentes posturas políticas y sociales sobre este tipo de eventos violentos suscitados en México.

Por último, para abordar el hecho estético de la pieza se partirá de la teoría planteada por Adolfo Sánchez Vázquez sobre la Estética de la Participación, ya que la relación que se da entre el arte y la tecnología permite de-construir técnica y socialmente la representación de la imagen a fin de crear nuevos lenguajes visuales como una forma de reflexionar sobre la construcción oficial de la historia.

\section{ABSTRACT}

This communication aims to analyze and reflect on how the concept of collective memory is constructed and resized through art. Violence that has arisen in Mexico since the war against drug trafficking has resulted in thousands of disappeared and hundreds of clandestine graves. Artists such as Rafael Lozano-Hemmer and his interactive installation "Level of Confidence" (2015) they have started from the use of digital technologies to enunciate and pronounce the violent social problems that have arisen in the country during the last years. So, beyond using art to represent crimes against humanity, what is at issue is to promote a collective conscience about forgetfulness, amnesia and the annihilation of the memory exercised by the State. 
In this sense, we will reflect on the philosophical texts of Tzvetan Todorov and Paul Ricoeur; In order to indicate how a society is involved with the violent events of its past, the way in which they affect it and the way to assimilate them.

Art is then manifested as a form of meaning that goes beyond history, by representing the story that occurred, as it presents us as part of the identities of the disappeared students of the Rural Normal School "Isidro Burgos". Thus, with the process of interaction and the intercrossing of information, the users of the facility build their own space of reflection in which different political and social positions converge on this type of violent events in Mexico.

Finally, to address the aesthetic fact of the piece will be based on the theory put forward by Adolfo Sánchez Vázquez on the "Aesthetics of Participation"; since the relationship between art and technology allows de-construct technically and socially the representation of the image, in order to create new visual languages as a way to reflect on the official construction of history.

\section{INTRODUCCIÓN}

La violencia suscitada en México a partir de la guerra contra el narcotráfico ha resultado en cientos de fosas clandestinas y miles de desaparecidos, entre ellos se encuentran los 43 estudiantes de la Escuela Normal Rural "Raúl Isidro Burgos" de Ayotzinapa desaparecidos el 26 de septiembre de 2014 en el municipio de Iguala, Guerrero, México. En el libro La noche de iguala. Secuestro, asesinato y narcotráfico en Guerrero (2018), Jorge Fernández menciona que:

A 123 kilómetros de distancia, en la localidad de Ayotzinapa, en el municipio de Tixtla, alrededor de 95 estudiantes de la Normal Rural Raúl Isidro Burgos se alistaban para, a bordo de dos camiones de la empresa Estrella de Oro -con números 1531 y 1568- que habían secuestrado la víspera, viajar a Chilpancingo y ahí recabar dinero para financiar su participación en la marcha conmemorativa de la matanza del 2 de octubre (Fernández Menéndez, 2018, pp. 19-20).

La marcha conmemorativa a la que asistirían los estudiantes se celebra año con año, cada 2 de octubre, en la Ciudad de México. El motivo principal es impedir el olvido de la masacre de Tlatelolco sucedida en 1968, cuando miles de estudiantes fueron asesinados por mandato del entonces presidente Gustavo Díaz Ordaz. Desde entonces, miles de personas se reúnen en la plaza de las Tres Culturas para marchar pacíficamente hacia el zócalo capitalino y pedir justicia. Con mantas que llevan consignas como "Ni perdón, ni olvido" los participantes mantienen viva la memoria colectiva de ese acontecimiento y, con el fin de impedir el olvido, transmiten de generación en generación el relato del evento. En el contingente participan estudiantes provenientes de distintas instituciones educativas públicas y sindicatos de trabajadores, por lo que -aquel 26 de septiembre de $2014-$ decenas de estudiantes de la Escuela Normal Rural secuestraron camiones para poder llegar a la capital del país y así participar en la marcha, tal como lo habían hecho varias de las generaciones anteriores; sin embargo, no imaginaron que la decisión de asistir los llevaría a ser parte de otra masacre.

El episodio violento, que aún es confuso, fue investigado por la Procuraduría General de la República (PGR) dentro del gobierno del expresidente Enrique Peña Nieto. Su versión es que la violencia suscitada en esa zona es producto de la disputa entre dos cárteles de narcotráfico. Además, se menciona que el entonces alcalde del municipio de Iguala, José Luis Abarca, y su esposa, María de los Ángeles Pineda Villa, son responsables de la desaparición de los 43 estudiantes y del asesinato de al menos 5 estudiantes más, pues al parecer el matrimonio mantenía vínculo directo con el grupo del crimen organizado conocido como Guerreros Unidos, el cual opera en la zona de los estados de Morelos y Guerrero. La interpretación de la PGR también menciona que la policía local tuvo participación directa, pues - bajo la orden de J. L. Abarca - abrió fuego contra los camiones que transportaban a los estudiantes.

La versión oficial que dio la PGR -y que fue establecida como "versión histórica" - ha sido cuestionada por algunos expertos externos, quienes señalan que hubo un mal manejo de la información, arresto ilegal de algunos sospechosos y el desconocimiento sobre el origen de algunas evidencias, por lo que familiares de los estudiantes y parte de la sociedad mexicana sienten descontento con la versión oficial de estos hechos. La postura de algunos artistas ha sido el pronunciamiento que va desde la expresión gráfica hasta la producción de instalaciones a fin de manifestar su descontento y visibilizar las problemáticas sociales que caracterizan a la sociedad contemporánea. Un ejemplo es la instalación interactiva Nivel de Confianza que, producida por el artista Rafael LozanoHemmer en el año 2015, intenta conmemorar el suceso.

La instalación consiste en una cámara de reconocimiento facial que ha sido entrenada para buscar incansablemente las caras de los estudiantes desaparecidos. Cuando [uno] se coloca frente a la cámara, el sistema utiliza algoritmos para encontrar qué rasgos faciales del estudiante se parecen más a los suyos y le da un "nivel de confianza" sobre el nivel de precisión de la coincidencia, en porcentaje.

Los algoritmos de vigilancia biométrica utilizados, -Eigen, Fisher y LBPH-, suelen ser utilizados por las fuerzas militares y policiales para buscar individuos sospechosos, mientras que en este proyecto se utilizan para buscar víctimas. La pieza siempre dejará de tener una coincidencia positiva, ya que sabemos que los estudiantes probablemente fueron asesinados y quemados en una masacre en la que 
participaron gobiernos, fuerzas policiales y cárteles de la droga, [por lo que,] la parte conmemorativa del proyecto es la búsqueda incansable de los estudiantes y la superposición de su imagen con los rasgos faciales del público (Lozano-Hemmer, 2015) ${ }^{1}$.

Partiendo de este contexto, nos dispondremos a analizar el cómo se construye la memoria colectiva, quién decide qué y cómo se recuerda; y la influencia que tienen los relatos y la narrativa de los acontecimientos en la construcción social de la memoria y en la interpretación personal de los hechos.

\section{DESARROLLO-METODOLOGÍA}

Se dice que la memoria pertenece al pasado porque mediante imágenes nos remonta a un tiempo pretérito, pero ¿cómo se construye la memoria en lo individual y en lo colectivo? Paul Ricoeur, en su libro La memoria, la historia, el olvido (2008), menciona que la memoria se relaciona con el proceso de rememorar ${ }^{2}$ que "consiste en hacer revivir el pasado evocándolo a varios, ayudándose mutuamente en hacer memoria de acontecimientos o de saberes compartidos: el recuerdo de uno sirve de reminder para los recuerdos del otro" (Ricoeur, 2008, p. 60). Asimismo, Ricoeur considera los planteamientos teóricos del filósofo Henri Bergson sobre el concepto de memoria:

"Es un acontecimiento de mi vida; esencialmente, lleva una fecha, que, por consiguiente, no puede repetirse. La imagen misma, considerada en sí, era necesariamente y en primer lugar lo que será siempre. Y también: El recuerdo es al instante perfecto; el tiempo no podrá añadir nada a su imagen sin desnaturalizarla; conservará para la memoria su lugar y su fecha. En una palabra: El recuerdo de esa lectura concreta es una representación, y solo una representación. [...] es privilegio del recuerdo-representación permitirnos remontar "la pendiente de nuestra vida pasada para buscar en ella cierta imagen »". (Ricoeur, 2008, p. 45).

Así pues, tanto para Paul Ricoeur como para Henri Bergson, la memoria es el resultado de una representación, del devenir-imagen del recuerdo. La rememoración construye a la memoria, trata de traer algo al presente "mediante la imagen presente de su ausencia desaparecida" (Ricoeur, 2008, p. 24) a efecto de proteger contra el olvido. Es así que en el proceso de rememoración lo importante no son las imágenes que nos llegan, sino el cómo nos llegan, es decir, cómo se crea la indicación de lo que hay que hacer para reconstruir un evento que depende de la dimensión intelectual y de la afectiva. Por ejemplo, en el arte, encontramos una infinidad de objetos que nos ayudan a recordar un tiempo pasado, inclusive un tiempo no vivido. Se trata de imágenes reproducidas en pinturas, esculturas, grabados, cerámica y arquitectura que adquieren la función de comunicar el pasado en el presente. La mayoría fueron creadas en virtud de representar cierta significación social, sentidos, valores y razones que eran parte del pensamiento social de ese momento. Por lo tanto, su modo de evocar ese pasado se da por la forma en que los objetos están organizados dentro del museo, archivos, bibliotecas o cualquier edificio que los albergue.

Incluso cuando no existieran este tipo de artefactos, el proceso de rememoración puede darse mediante la palabra, es decir, la imagen puede ser reproducida mentalmente a través de su descripción física o afectiva. Sin embargo, cuando se trata de construir la memoria colectiva, el proceso de rememoración ve más allá de lo individual, ya que involucra a los otros. El pensamiento colectivo surge así de la fusión de narraciones individuales y a su vez los pensamientos individuales son constructos sociales que emergen de la interacción social con los otros. Al respecto, Maurice Halbwachs comentaba que la memoria colectiva es "un proceso social de reconstrucción de un pasado significativo para una colectividad" (Mendoza García, 2014, p. 104). Por lo tanto, la colectividad es la encargada de dirigir el qué y cómo se recuerda. Son las conmemoraciones, los discursos y las manifestaciones, los indicadores que ayudan a una colectividad a reivindicar su pasado en un intento por transmitir a las nuevas generaciones la memoria que les compete. Pero, en cualquiera de los casos, estos indicadores no se celebran en fechas oficiales, pues su razón de ser se encuentra precisamente en la denuncia y en la protesta cuyo objetivo es dar continuidad a un pasado que se signifique en el presente para no producir el olvido.

De ahí que algunas colectividades hayan empleado este tipo de prácticas como una forma de sanar los duelos colectivos y reconocer el sentir de la comunidad. Es el caso de las tragedias, de las guerras y de los eventos violentos sucedidos a lo largo de la historia en donde los sobrevivientes narran sus dolores con la finalidad de esclarecer la verdad y difundir los hechos según su experiencia de vida, pues en muchas ocasiones sus narraciones se confrontan con las versiones oficiales que, establecidas por el poder, han sido difundidas como verdad histórica. "Es por esto por lo que los muertos demandan a los vivos: recordadlo todo y contadlo; no solamente para combatir los campos sino también para que nuestra vida, al dejar de sí una huella, conserve su sentido." (Todorov, 2004, p. 103).

\footnotetext{
${ }^{1}$ Para más información: http://www.lozano-hemmer.com/level_of_confidence.php

${ }^{2}$ Rememorar - del latín rememorāre - significa recordar, pasar a tener en la mente algo del pasado (Real Academia Española).
} 
Cierto es que la memoria, a diferencia de la historia, se formula desde la interpretación colectiva de los hechos que incluye no sólo la creación de objetos de significado, sino también la participación ciudadana en las prácticas sociales. La historia oficial, por el contrario, se escribe con base en una ideología política que expone tanto los relatos nacionales que enaltecen la idealización e identidad de la institución a la que representan como las narraciones construidas desde un pensamiento artificial y esquematizado que da continuidad a la relación de los hechos bajo una tradición positivista. Dicho de otro modo: si la memoria se construye en un límite de líneas irregulares e inciertas, la historia lo hace sobre líneas de separación netamente trazadas.

En ese sentido, Maurice Halbwachs comentaba que la memoria colectiva, además de ser producida por la fusión de recuerdos, está inscrita en tres marcos sociales identificados como: el tiempo, el espacio y el lenguaje, los cuales, a través de la interacción social, logran estipular contextos que apoyan a la comprensión de su presente continuo.

Los marcos son, entonces, más sociales y simbólicos que físicos y secuenciales: son significativos en la medida que se convienen colectivamente y se estipulan para las colectividades: una fecha y un lugar resultan de interés para la gente en la medida que les "dicen" algo, que los interpelan, que les comunican algo significativo, de lo contrario serían fechas y lugares distantes, sin interés, ajenos e incomunicables. (Juárez Romero, Arciga Bernal \& Mendoza García, 2012, p. 18).

En el marco social del tiempo se interpreta y se comprende la vida en grupo. Los recuerdos toman sentido en el tiempo, pues son las vivencias de los individuos las que, a partir de su encuentro con el pasado, le dan sentido al presente y proyectan en el futuro su identidad y su pensamiento social. El tiempo es importante porque a través de él las personas reconocen los lazos con sus semejantes, por lo que la desaparición de los 43 estudiantes en el año 2014 se unió a la conmemoración de la masacre de Tlatelolco de 1968 redimensionando con cada imagen narrada la construcción social de la memoria y marcando de manera secuencial el pensamiento colectivo sobre la violencia y el olvido.

[Son] los individuos [quienes] formulan sus puntos de vista, organizan sus actitudes y construyen el significado de sus comportamientos, [relacionándolos] con la experiencia que se desprende de la interacción con los grupos en los que participa y con los que contiende en la definición de su realidad social. Esto es que los grupos humanos producen sus valores, sus conocimientos y con ello su memoria de los hechos sociales. (Juárez Romero, Arciga Bernal, \& Mendoza García, 2012, p.103).

A su vez, en el marco social del espacio, la memoria permite ubicar un lugar. A este marco le corresponde la expresión simbólica del lenguaje y de las relaciones humanas que en él se establecen. En la espacialidad la memoria reconstruye los acontecimientos desde varias versiones y miradas colectivas, su multiplicidad narrativa se ve enriquecida por la gama de relaciones interpersonales que se producen al interior y al exterior del grupo; por lo tanto, los relatos son contados desde dentro y no desde afuera como lo hace la historia.

En el marco espacial de la memoria, los lugares también adquieren un significado cultural a partir de la participación ciudadana, pues cada vez que se sugiere que en ese sitio ocurrió un acontecimiento, el espacio se transforma en un escenario que adquiere vida. Cierto es que cuando se comunica un hecho del que se ha sido testigo, generalmente, se recurre a la mención de los otros y -como referentes del espacio- a los valores, las emociones y los objetos dispuestos en el lugar. De esa manera, los pensamientos, los acontecimientos y las asociaciones del cotidiano encuentran su significado en el tiempo y el espacio.

El lenguaje será el otro marco social complementario del tiempo y del espacio. A través de él se materializan los recuerdos y se objetivan las relaciones sociales. En él se versa la idea y la temporalidad de los hechos. Su expresión puede ser oral, escrita o pictográfica. Por medio del lenguaje se construyen, se conservan y se transmiten los contenidos y significados de la memoria. En el caso de los objetos de arte el lenguaje va relacionado con la dimensión simbólica y en las prácticas artísticas el lenguaje se asocia a la interpretación de los hechos, a las acciones, a las costumbres y a las tradiciones.

La participación estética que se produce en la instalación Nivel de Confianza genera más un espacio de reflexión que de contemplación. En ella, los algoritmos de vigilancia biométrica funcionan como el lenguaje visual que permite la rememoración del hecho y da significado a la violencia ejercida de forma transgeneracional sobre los estudiantes mexicanos. Asimismo, las similitudes que se encuentran entre los rasgos faciales del público participante y los rostros de los 43 estudiantes reconstruyen la memoria colectiva con base en la reinvidicación social de la justicia y en nombrar lo ausente como algo que sigue estando presente (Figura 1 , 2).

El sofware de reconocimiento facial además permite que en cada exhibición se rememore el hecho violento como una forma de impedir el olvido. En consecuencia, la comunicación que se produce entre los participantes va más allá de las simples palabras, pues algunas imágenes es imposible verbalizarlas, por lo que las imágenes no visibles de este hecho se construyen en la imaginación y en el recuerdo. La memoria recurre al espacio social de las ideas para verbalizar los hechos y reconocer el comportamiento colectivo ante un acontecimiento violento. Por su parte, las actividades sociales del recuerdo y la reconstrucción compartida de un acontecimiento contribuyen a reforzar la cohesión social y a mantener las creencias colectivas bajo el vínculo fundamental de la memoria y la afectividad, pues ésta última puede ser considerada el principal estímulo para tomar una postura sobre dicho 
Rojas Cuevas, Rosa Maribel.

Cómo se redimensiona la construcción social de la memoria en el México actual: un caso de arte interactivo.

IV CONGRESO INTERNACIONAL DE INVESTIGACIÓN EN ARTES VISUALES ANIAV 2019

IMAGEN [N] VISIBLE

http://dx.doi.org/10.4995/ANIAV.2019.9607

acontecimiento dado que son las emociones el reflejo de las ideas socioculturales y valores relacionados con el desarrollo moral e intelectual de los individuos de una sociedad.
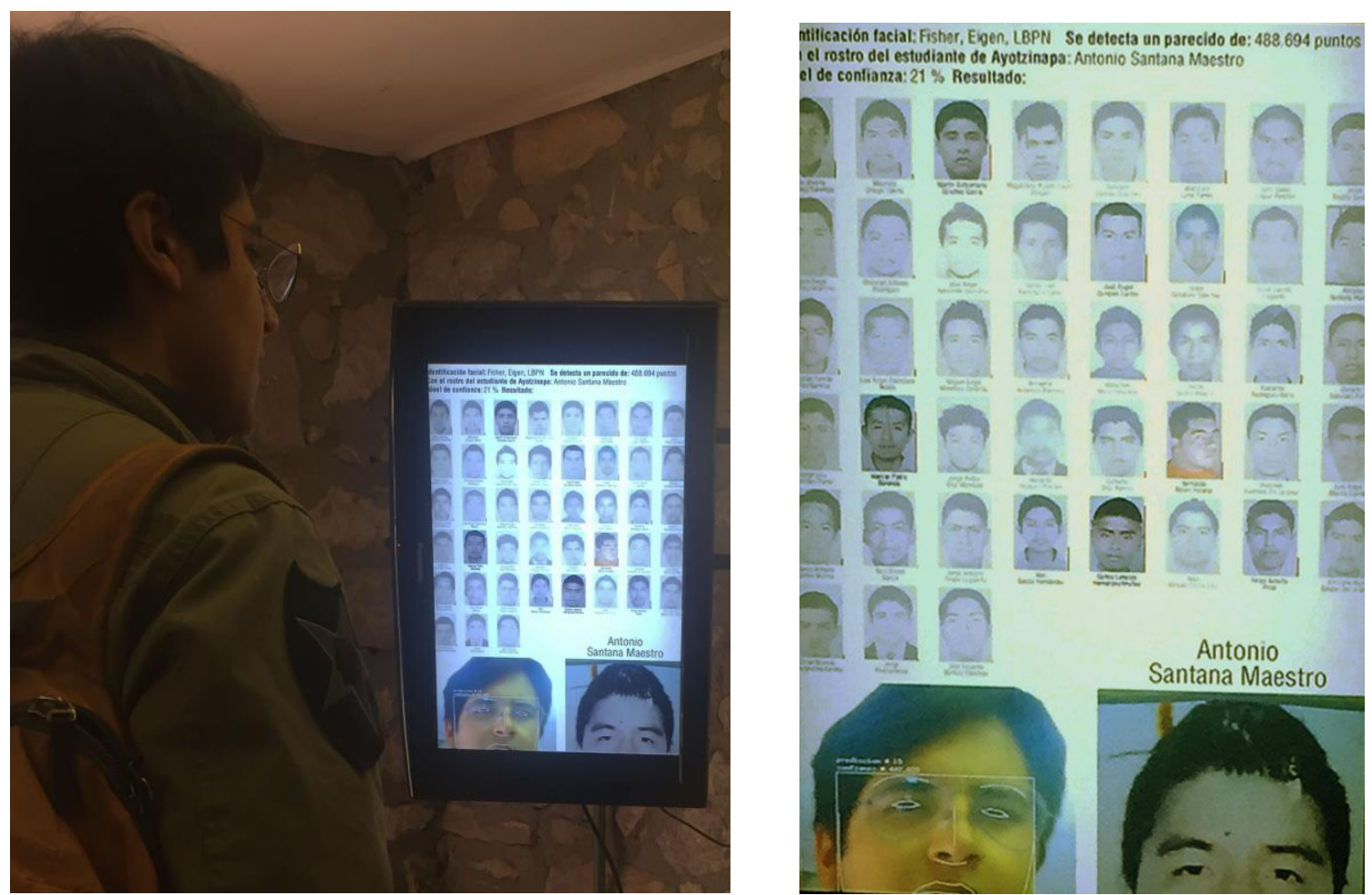

Figura 1, 2. "NIVEL DE CONFIANZA", Rafael Lozano-Hemmer, 2015. Elaboración propia.

\section{CONCLUSIONES}

La participación interactiva que se produce en Nivel de Confianza permite observar con especial singularidad la recepción y la interpretación colectiva sobre la desaparición forzada de los 43 estudiantes. La instalación funciona como artefacto que ayuda al público a rememorar el evento violento reconociendo la incertidumbre y el duelo colectivo que aún padece la sociedad. En este sentido, la rememoración que se produce más que dar importancia a la representación icónica o escrita de la violencia lo que promueve es un diálogo en torno al significado de la memoria, la violencia y la justicia. Es una pieza artística que reúne una colectividad para conmemorar un hecho doloso de forma solemne y reflexiva. Las imágenes mentales que resultan no sólo dependen de la dimensión intelectual en la que son representadas y significadas, sino también de la dimensión afectiva que las narraciones y los relatos colectivos le han asignado.

El público participante de la instalación también advierte que para sentir empatía con los familiares de los desaparecidos no es necesario representar la violencia de forma literal, pues basta con encontrar un parecido físico para imaginar ser uno ellos. Así, mientras el arte mimético obedece a la estructura de una representación ideológica y le apuesta a la lentitud de su contemplación, el arte interactivo objetiva con un lenguaje electrónico una serie de significados y relaciones espacio-temporales que le ayudan al participante a entender su pasado. Sin embargo, debido al carácter efímero de la pieza, es posible que el significado y la apreciación de la atrocidad corran el riesgo de ser diluidos en el tiempo y el espacio. Si, anteriormente, el arte representaba de manera mimética el acontecer significativo, con este tipo de manifestaciones artísticas, el artefacto ya no queda como registro, sino la trascendencia de la experiencia estética y colectiva.

Por último, la participación activa, tanto en las prácticas sociales como en las prácticas artísticas, expone los valores, el pensamiento y la interpretación del acontecer socio-histórico que moldean la identidad y redimensionan la construcción social de la memoria en México que, desafortunadamente, visibilizará en el futuro el problema de la corrupción y el nivel de violencia en la que vive y de la que es participe la sociedad mexicana. 


\section{FUENTES REFERENCIALES}

Bergson, H. (2006). Materia y memoria. Ensayo sobre la relación del cuerpo con el espíritu. Buenos Aires: Cactus.

Fernández Menéndez, J. (2018). La noche de Iguala. Secuestro, asesinato y narcotráfico en Guerrero. México: Ediciones Cal y Arena.

Halbwachs, M. (2004). La memoria colectiva. Zaragoza: Prensas Universitarias de Zaragoza.

Juárez Romero, J., Arciga Bernal, S., Mendoza García, J. (2012). Memoria colectiva. Procesos psicosociales. México: Universidad Autónoma Metropolitana/Porrúa.

Lozano, H. R. (2015). Nivel de Confianza. Recuperado de http://www.lozano-hemmer.com/level of confidence.php

Mendoza García, J. (2014). La configuración de la memoria colectiva: los artefactos. Por caso, la escritura y las imágenes. Entreciencias: Diálogos en la Sociedad del Conocimiento, 2 (3), 103-119.

Real Academia Española. (s.f.). Rememorar. Diccionario de la lengua española. Recuperado de https://dle.rae.es/?id=VtCji3T

Ricoeur, P. (2008). La memoria, la historia, el olvido. Buenos Aires: Fondo de Cultura Económica.

Todorov, T. (2004). Frente al límite. México: Siglo XXI. 